\title{
Effect of argon ion energy on the performance of silicon nitridemultilayer permeation barriers grown by hot-wire CVD on polymers
}

\author{
P. Alpuim, ${ }^{\mathrm{a}, \mathrm{b}}$, S.Majee ${ }^{\mathrm{c}}$, M.F. Cerqueira ${ }^{\mathrm{a}}$, D. Tondelier ${ }^{\mathrm{c}}$, B. Geffroy ${ }^{\mathrm{c}, \mathrm{d}}$, Y. Bonnassieux $^{\mathrm{c}}$, \\ J.E. Bourée ${ }^{\mathrm{c}, *}$ \\ ${ }^{a}$ Centro de Física, Universidade do Minho, 4710-057 Braga, Portugal \\ b INL, International Iberian Nanotechnology Laboratory, 4715-330 Braga, Portugal \\ ${ }^{c}$ Laboratoire de Physique des Interfaces et des Couches Minces, CNRS UMR 7647, \\ Ecole Polytechnique, Université Paris-Saclay, 91128 Palaiseau, France \\ ${ }^{\mathrm{d}}$ Laboratoire d'Innovation de Chimie des Surfaces et des Nanomatériaux, \\ IRAMIS/NIMBE, CNRS UMR 3685, CEA Saclay, 91191 Gif-sur-Yvette, France
}

Keywords: Silicon nitride; Hot-wire CVD; Low-temperature deposition; Ar plasma treatment; Permeation barrier; Polymer substrate

\begin{abstract}
Permeation barriers for organic electronic devices on polymer flexible substrates were realized by combining stacked silicon nitride ( $\mathrm{SiNx})$ single layers $(50 \mathrm{~nm}$ thick) deposited by hot-wire chemical vapor deposition process at low-temperature $\left(\sim 100^{\circ} \mathrm{C}\right)$ with a specific argon plasma treatment between two successive layers.

Several plasma parameters (RF power density, pressure, treatment duration) as well as the number of single layers have been explored in order to improve the quality of permeation barriers deposited on polyethylene terephthalate. In this work, maximumion energy was highlighted as the crucial parameter making it possible to minimize water vapor transmission rate (WVTR), as determined by the electrical calcium test method, all the other parameters being kept fixed. Thus fixing the plasma treatment duration at 8 min for a stack of two SiNx single layers, a minimum WVTR of $5 \times 10^{-4} \mathrm{~g} /\left(\mathrm{m}^{2}\right.$ day), measured at room temperature, was found for a maximum ion energy of $\sim 30 \mathrm{eV}$. This minimum WVTR value was reduced to $7 \times 10^{-5} \mathrm{~g} /\left(\mathrm{m}^{2}\right.$ day) for a stack of five SiNx single layers. The reduction in the permeability is interpreted as due to the rearrangement of atoms at the interfaces when average transferred ion energy to target atoms exceeds threshold displacement energy.
\end{abstract}

\section{Introduction}

The future of organic electronic devices such as organic light emitting diodes (OLEDs) or organic photovoltaic cells is only conceivable if the glass is replaced with plastic, which would reduce the weight, increase the flexibility and increase the potential for low-cost roll to roll manufacturing processes. However the low-temperature stability of organic polymer substrates demands an adaptation of the processes to the temperatures of $150^{\circ} \mathrm{C}$ or less so as not to impair the electronic device performance [1]. Moreover the 
high permeability of plastics to atmospheric gases such as $\mathrm{H} 2 \mathrm{O}$ and $\mathrm{O} 2$ as well as the high oxidation of low work function alkali-metal cathodes are key issues for the development of flexible OLEDs [2-4]. Thus gas diffusion (permeation) barriers deposited on plastics at low-temperatures are essential. For stable device operation, especially for OLEDS in comparison with organic transistors or organic solar cells, a water vapor transmission rate (WVTR) on the order of $10^{-6} \mathrm{~g} /\left(\mathrm{m}^{2}\right.$ day) is mandatory [5], which is six orders of magnitude lower than that needed for the sealing of food packages. At this point it is interesting to trace most part of the studies to date on permeation barriers for plastic electronic devices in order to position the original approach of the present work. Since the beginning, the common way to encapsulate OLEDs was the use of a glass or metal lid and a desiccant material, the whole being sealed by epoxy resin [6,7], a technique which was incompatible with flexible plastic substrates or transparent devices. As display panel manufacturers required thinner panels for very slim and lightweight designs, the second step consisted in depositing on polyethylene terephthalate (PET) and polyethylene naphthalate substrates single layer barriers based on oxides and nitrides using conventional deposition techniques, like plasma-enhanced chemical vapor deposition (PE-CVD), hot-wire chemical vapor deposition (HWCVD), physical vapor deposition, reactive sputtering, atomic layer deposition (ALD) and plasma-enhanced atomic layer deposition (PE-ALD). Typical WVTR values of $10^{-2} \mathrm{~g} /\left(\mathrm{m}^{2}\right.$ day) have been measured at $38^{\circ} \mathrm{C}$ and $85 \%$ relative humidity $(\mathrm{RH})$ for most of the techniques [8-11], except a lower value of $\sim 10-3 \mathrm{~g} /(\mathrm{m} 2$ day) which was measured for ALD or PE-ALD barriers $[12,13]$, provided that the critical thickness (defined, for a given material, as the minimum thickness producing the maximum reduction of WVTR [8]) was achieved. So critical thicknesses of $\sim 45 \mathrm{~nm}$ for silicon nitride $\left(\mathrm{SiN}_{\mathrm{x}}\right)$ [9] and $\mathrm{SiO}_{\mathrm{x}} \mathrm{C}_{\mathrm{y}}$ [10] and of $\sim 25 \mathrm{~nm}$ for alumina $\left(\mathrm{Al}_{2} \mathrm{O}_{3}\right)$ [12] have been assessed, respectively. The improvement of properties of an ALD barrier can be ascribed to the low-temperature ALD process known for growing dense, highly conformal and pinhole-free films with low stress [14], even on a polymer surface which is porous, defective and not particle free. Assuming, in the following discussion, that the average density of large defects such as pinholes (with a size from $10 \mathrm{~nm}$ to $1 \mu \mathrm{m}$ ) on the polymer substrate is very low $\left(<10 \mathrm{~cm}^{-2}\right)$, it is widely acknowledged that the permeation in single layer inorganic barriers is attributed to local defects (defects with a $\mathrm{nm}$ size) in the film caused by the deposition process or to nodular defects at places of particles on the substrate $[11,15,16]$. The third step, first reported in 1994 [17] and adopted by many groups, consisted in the fabrication of multilayer organic-inorganic barriers by coating the polymer substrate with alternating layers of acrylate polymerfor planarization of the polymer surface - and an inorganic oxide barrier layer [18]. Going further in many multilayer systems, at least two barrier layers (with intrinsic high stiffness) were used and separated by a more elastic polymer interlayer. This smoothing interlayer was used to interrupt the growth of nanodefects in the inorganic barriers, to planarize particles located on the substrate surface and to reduce mechanical stress compared to that of the inorganic layers [2,18-25]. Finally the role of this interlayer was to lengthen the path of diffusion for permeate through the whole barrier thickness or equivalently to increase its diffusion time (also called lag-time) and consequently to reduce the permeation rate through the barrier. Thus it can be assumed that the organic/inorganic hybrid multilayer barriers solve the apparent conflict between flexibility (needed to withstand external stress applied by bending as well as internal stresses generated during deposition of the barrier layers) and barrier performance for plastic electronic devices. This explains why so many groups realized hybrid multilayer barriers using different combinations of deposition techniques: initiated chemical vapor 
deposition (iCVD), molecular layer deposition (MLD) or PE-CVD for the deposition of organic polymer layers and ALD, PE-ALD, magnetron sputtering, PE-CVD or HWCVD for the deposition of inorganic layers respectively [23,25-33]. The iCVD, a variant of HWCVD, is a low-temperature process where an initiator is thermally activated for the initiation of surface polymerization, resulting in a thin polymer film of high purity with extreme conformality [34]. The MLD process is a subtype of ALD and therefore uses sequential self-limiting surface reactions for deposition [35]. As salient results, diffusion barrier stacks combining inorganic $\mathrm{Al}_{2} \mathrm{O}_{3} / \mathrm{SiO}_{2}$ ALD bilayers with organic aluminium alkoxide MLD layers were realized for the encapsulation of organic electronics, with WVTRs of as low as $10^{-5} \mathrm{~g} /\left(\mathrm{m}^{2}\right.$ day) measured at $38^{\circ} \mathrm{C}$ and $32 \% \mathrm{RH}$ and exhibiting improved stress resistance [31]. Similarly, highly bendable permeation barriers combining hybrid multilayers of $\mathrm{Al}_{2} \mathrm{O}_{3}$ ALD/PE-CVD grown plasma polymer were realized and tested with a WVTR of $3 \times 10^{-4} \mathrm{~g} /\left(\mathrm{m}^{2}\right.$ day $)$ at $85^{\circ} \mathrm{C}$ and $85 \% \mathrm{RH}$ without deterioration, even after 10000 bending cycles at a bending radius of $0.3 \mathrm{~cm}$ [32,33].

Unlike the hybrid approach, a specific study reporting a completely organic encapsulation (thus totally flexible) system using alternate stacks of two organic materials having different glass-transition temperatures of around $100^{\circ} \mathrm{C}\left(64^{\circ} \mathrm{C}\right.$ and $108^{\circ} \mathrm{C}$, respectively) showed a lifetime limited to $10 \mathrm{~h}$ for an OLED [36], which is far from sufficient. This poor result can be explained by the much higher (several orders of magnitude) diffusivity and solubility for water vapor through a polymer layer than through any inorganic layer having the same thickness [18].

Thus several groups have chosen an intermediate way by focusing on the improvement of the barrier properties rather than solving the flexibility problem: they deposited ultrathin inorganic (essentially $\mathrm{Al}_{2} \mathrm{O}_{3}$ ) layers using ALD or PE-ALD [12,13,37]. However, as $\mathrm{Al}_{2} \mathrm{O}_{3}$ ALD barriers are vulnerable to corrosion by water [38], it was observed that multilayer barriers consisting of alternating inorganic layers of $\mathrm{Al}_{2} \mathrm{O}_{3}$ and $\mathrm{SiO}_{2}$ [38], of $\mathrm{Al}_{2} \mathrm{O}_{3}$ and $\mathrm{ZrO}_{2}$ [39-41], or of $\mathrm{Al}_{2} \mathrm{O}_{3}$ and $\mathrm{SiN}_{\mathrm{x}}$ [15, 42] could prevent this corrosion and improved significantly the barrier performance: a WVTR below $10^{-5}$ $\mathrm{g} /\left(\mathrm{m}^{2}\right.$ day $)$ was measured at room temperature in every case, allowing for device lifetimes in excess of $10000 \mathrm{~h}$ [39]. All of these studies led to the conclusion that $\mathrm{SiO}_{2}$, $\mathrm{ZrO}_{2}$, or $\mathrm{SiN}_{\mathrm{x}}$ layers were filling nanodefects in the $\mathrm{Al}_{2} \mathrm{O}_{3}$ layers or forming a new phase at the interfaces, stabilizing the bilayer coating [38,40,42], which could explain the decrease in permeability. In the same way multiple pairs of $\mathrm{MgF}_{2} / \mathrm{ZnS}$ bilayers grown by vacuum thermal deposition [43] as well as $\mathrm{SiN} / \mathrm{SiCN} / \mathrm{SiN}$ nanolaminated multilayers grown by PE-CVD at low working pressure [44] exhibited long-term stable permeation barrier properties with a WVTR below $10^{-5} \mathrm{~g} /\left(\mathrm{m}^{2}\right.$ day $)$ at $85^{\circ} \mathrm{C}$ and $85 \%$ RH.

The objective of the present work is to implement the intermediate way for improving multilayer permeation barriers by replacing the alternating inorganic layers of $\mathrm{Al} 2 \mathrm{O} 3$ and $\mathrm{SiO} 2$, etc.... with inorganic $\mathrm{SiN}_{\mathrm{x}}$ single layers grown by HWCVD separated by a specific plasma treatment between two successive layers. $\mathrm{SiN}_{\mathrm{x}}$ has been chosen because, contrary to $\mathrm{Al}_{2} \mathrm{O}_{3}$, it is not vulnerable to corrosion by water whereas HWCVD has been selected as the deposition technique at low temperature, instead of the standard PE-CVD, because the hydrogen content inside the $\operatorname{SiN}_{x}$ film is lower, so the film density is higher, leading to a lower probability of diffusion pathways for the permeate $[45,46]$. HWCVD growth rate is also much higher than ALD growth rate $[38,42]$. One of the main claims for ion beam assisted deposition is that high quality deposits can be obtained at lower substrate temperature, thus avoiding large scale interdiffusion which 
results from high temperature processing. So the use of a low-energy plasma treatment at sufficiently low-temperature $\left(\sim 100^{\circ} \mathrm{C}\right)$ should allow for a surface smoothening and a rearrangement of the surface atoms of the $\mathrm{SiN}_{\mathrm{x}}$ layers, thus decoupling the structural nanodefects in the successive single layers and leading to an improvement of the gas diffusion barrier. This paper reports on the detailed study of the different parameters controlling the ion energy in the plasma and how they can impact the permeation barrier performance assessed through the electrical calcium degradation test.

\section{Experimental details}

\subsection{HWCVD deposition of $\mathrm{SiN}_{\underline{x}}$ films}

For depositing $\mathrm{SiN}_{\mathrm{x}}$ films by HWCVD, a single coil shaped tantalum (Ta) filament acting as a catalyst is heated up to $2000^{\circ} \mathrm{C}$ and provides the surface for heterogeneous thermal decomposition of the incoming gases (silane and ammonia diluted in hydrogen) into radical species, which are the precursors for the amorphous silicon nitride $\left(\mathrm{a}-\mathrm{SiN}_{\mathrm{x}}\right)$ film growth. The plastic substrates used throughout this work are $175 \mu \mathrm{m}$ thick heatstabilized PET (Melinex ST504, DuPont Teijin Films) with a stiffness of $3 \times 10^{-3}$ N.m, planarized on one side. This polymer is a semicrystalline polyester whose glasstransition temperature is $78^{\circ} \mathrm{C}$ and melting temperature is $255^{\circ} \mathrm{C}$, with an upper temperature for processing of around $150^{\circ} \mathrm{C}$. These substrates are rinsed and loaded into the reactor residing in a laminar-flow hood operated at class 1000 clean room conditions. In order to limit as much as possible the substrate temperature during the growth to $100^{\circ} \mathrm{C}$, due to the increase of temperature with time induced by the hot filament [47], the filament to substrate distance has been increased up to $7.5 \mathrm{~cm}$. This limitation to $100^{\circ} \mathrm{C}$ induces automatically a limit of $45-50 \mathrm{~nm}$ to the $\mathrm{SiN}_{\mathrm{x}}$ single layer thickness [48]. Even under these conditions, an increase of average surface roughness for PET substrate from $1.35 \mathrm{~nm}$ to $55 \mathrm{~nm}$ is observed when the substrate temperature exceeds the glass-transition temperature [48]. The working gas pressure is fixed at 3.3 $\mathrm{Pa}$ for all depositions.

\subsection{Choice of plasma species}

In the framework of an elastic collision between an incoming ion $\left(\mathrm{M}_{1}\right)$ of maximum kinetic energy Emax and an atom at rest in a target $\left(\mathrm{M}_{2}\right)$, the maximum energy transfer ET from incoming ion to target atom is equal to $4 M_{1} M_{2} /\left(M_{1}+M_{2}\right)^{2}$ times $E_{\max }$. As oxygen $(\mathrm{O})$ cannot be chosen because of its reactivity, argon (Ar) is the best choice as plasma species for interacting with silicon $(\mathrm{Si})$ atoms: ET = 0.97 Emax. On the contrary it may be noted that $\mathrm{Ar}$ is not the best choice for interacting with nitrogen $(\mathrm{N})$ atoms: $\mathrm{ET}=0.77 \mathrm{E}_{\max }$.

\subsection{Plasma treatment of $\mathrm{SiN}_{\underline{x}}$ films}

The Ar plasma treatment between successive $\mathrm{SiN}_{\mathrm{x}}$ single layers is carried out in a glow discharge chamber using a $13.56 \mathrm{MHz} \mathrm{RF}$ generator, where the sample is clamped to the grounded electrode. The sequence of film deposition in the HWCVD chamber and Ar treatment in the PE-CVD chamber is performed without breaking the vacuum by moving the sample between the two chambers connected by a gate valve $[49,50]$. A power density of $350 \mathrm{~mW} / \mathrm{cm}^{2}$ and a working pressure of $6.7 \mathrm{~Pa}$ are generally adopted, 
but as maximum energy of Ar ions depends in different ways on power density and pressure, these two parameters have been varied in the ranges 85 to $700 \mathrm{~mW} / \mathrm{cm}^{2}$ and 3.3 to $10 \mathrm{~Pa}$, respectively (see Table 1 ). The third plasma parameter controlling directly the ion fluence (also called ion dose) is the treatment duration which varied in the range 0 to $15 \mathrm{~min}$. Under these conditions, the time-averaged potential difference between the plasma and the grounded substrate electrode represents the energy (in eV) of the ions striking the substrate; the observed unimodal ion energy distribution is a relatively narrow peak with the high energy edge representing the maximum sheath potential drop (maximum plasma potential, which is measured) [51,52].

\subsection{Analysis techniques}

The films have been characterized by atomic force microscopy for the evaluation of average surface roughness, by UV-visible phase modulated spectroscopic ellipsometry for the determination of refractive index and thickness, by X-ray reflectometry (XRR) for the determination of surface roughness and mass density, by X-ray photoelectron spectroscopy (XPS) and glow discharge optical emission spectroscopy (GD-OES) for surface and profilometry chemical composition respectively. The reflectance and transmittance curves of films on plastics, measured using an integrated sphere, are used to check their compatibility for utilization in organic devices. In some occasions, Fourier transformed infrared spectroscopy (FTIR) was used to determine the density of specific chemical bonds inside the films (e.g. $\mathrm{Si}-\mathrm{H}, \mathrm{N}-\mathrm{H}$ and $\mathrm{Si}-\mathrm{N}$ ).

The WVTR (amount of water molecules diffusing through a unit area of the barrier film per unit time under the conditions of test) and the lag-time (time required for the water molecules to diffuse through the whole thickness of the barrier layer) are evaluated using the electrical calcium (Ca) degradation test method under ambient atmospheric conditions. The WVTR value is deduced from the average decrease of conductance of a thin $\mathrm{Ca}$ layer versus time, resulting from the reactivity of $\mathrm{Ca}$ with water molecules [5355]. For details regarding the applied Ca test design, the set-up and the implementation of this method, see [49] (the $\mathrm{Ca}$ area covered inside the Al contact electrodes is 0.7 $\mathrm{cm}^{2}$ ). All operations to fabricate the test cells are carried out in a nitrogen atmosphere glove box. For uncoated PET substrate (175 $\mu \mathrm{m}$ thick), WVTR evaluated through 10 independent measurements was $0.14 \pm 0.04 \mathrm{~g} /\left(\mathrm{m}^{2}\right.$ day $)$, whereas the WVTR measured for glass substrate was $\sim 10-6 \mathrm{~g} /\left(\mathrm{m}^{2}\right.$ day) [49]. 
Table 1: MaximumAr ion energy as a function of RF power density and gas pressure for the intermediate plasma treatments.

\begin{tabular}{lcccl}
\hline $\begin{array}{l}\text { Power } \\
\text { density, } \mathrm{P}_{\mathrm{w}} \\
\left(\mathrm{mW} / \mathrm{cm}^{2}\right)\end{array}$ & $\begin{array}{l}\text { Pressure, } \mathrm{p}_{\mathrm{g}} \\
(\mathrm{Pa})\end{array}$ & $\begin{array}{l}\mathrm{V}_{\text {Bas }} \\
(\mathrm{V})\end{array}$ & $\begin{array}{l}\text { Maximum ion } \\
\text { energy, } \mathrm{E}_{\max } \\
(\mathrm{eV})\end{array}$ & $\begin{array}{l}\text { Treatment } \\
\text { duration, } \mathrm{t} \\
(\mathrm{s})\end{array}$ \\
\hline 85 & 6.7 & -10 & 10 & 480 \\
350 & 10 & -18 & 18 & 480 \\
350 & 6.7 & -20 & 20 & 480 \\
350 & 3.3 & -22 & 22 & 480 \\
400 & 6.7 & -28 & 28 & 480 \\
400 & 3.3 & -30 & 30 & 480 \\
450 & 6.7 & -38 & 38 & 480 \\
700 & 6.7 & -100 & 100 & 480 \\
\hline
\end{tabular}

\section{Results and discussion}

As reported previously [48,49], silicon nitride films grown by HWCVD on crystalline silicon (c-Si) substrate and on PET foil at low-temperature $\left(\sim 100^{\circ} \mathrm{C}\right)$ are amorphous (a$\mathrm{SiN}_{\mathrm{x}}$ ), as confirmed by X-ray diffraction patterns. These films were optimized as concern their optical transmittance, refractive index and deposition rate by playing with the three parameters: the flow rate ratio ammonia/silane, the hydrogen dilution of the reactant gases and the Ta filament current. For a flow rate ratio of 2, a hydrogen dilution of $90 \%$ and a filament current of $16 \mathrm{~A}$, corresponding to a filament temperature of $2000^{\circ} \mathrm{C}$, films having a transmittance higher than $80 \%$ over the visible range of the spectrum, a refractive index of 2.01 at $633 \mathrm{~nm}$ (close to 2.05 found for stoichiometric amorphous $\mathrm{Si}_{3} \mathrm{~N}_{4}$ ) and a deposition rate of $0.12 \mathrm{~nm} / \mathrm{s}$ were obtained. Considering the deposition time for the HWCVD process ( 400 s), $\sim 50 \mathrm{~nm}$ thick films could be deposited with a substrate temperature not exceeding $100^{\circ} \mathrm{C}$, which thickness value is equivalent to the critical thickness determined for the $\mathrm{SiN}_{\mathrm{x}}$ films grown on PET with a WVTR of $1.3 \times 10^{-2} \mathrm{~g} /\left(\mathrm{m}^{2}\right.$ day $)[48,50]$.

It is expected that by stacking several $\mathrm{SiN}_{\mathrm{x}}$ single layers, each having a thickness equal to the critical thickness $(\sim 50 \mathrm{~nm})$, it will give rise to a very efficient permeation barrier with a drastically reduced WVTR value. When the number of stacked single layers increases from one to five (the multilayer thickness increasing from $50 \mathrm{~nm}$ to $250 \mathrm{~nm}$ ), a decrease in WVTR from $1.3 \times 10^{-2} \mathrm{~g} /\left(\mathrm{m}^{2}\right.$ day $)$ to $8 \times 10^{-3} \mathrm{~g} /\left(\mathrm{m}^{2}\right.$ day $)$ as well as an increase in lag-time from 2 to $15 \mathrm{~h}$ were observed [48]. This slight decrease (10\%) of WVTR from one single layer to the following one is insufficient. Such a simple multilayer structure is far from attaining the required barrier performance $<10^{-5} \mathrm{~g} /\left(\mathrm{m}^{2}\right.$ day). It has been concluded that the density of nanodefects was higher in HWCVD grown $\mathrm{SiN}_{\mathrm{x}}$ than in a-SiN $\mathrm{x}_{\mathrm{x}}$ deposited at high temperature, which is corroborated by the slightly lower refractive index (2.01) or the slightly lower mass density $\left(2.83 \mathrm{~g} / \mathrm{cm}^{3}\right)$ compared to the values for stoichiometric amorphous $\mathrm{Si}_{3} \mathrm{~N}_{4}\left(2.05\right.$ and $3.1 \mathrm{~g} / \mathrm{cm}^{3}$, respectively). Another explanation for this insufficient permeation barrier performance was given recently, based on the size and density of pores inside the bulk of the inorganic layers [16]: compared to the diameter of $\mathrm{H}_{2} \mathrm{O}$ molecule $(0.27 \mathrm{~nm})$, it was shown that pores larger than $1 \mathrm{~nm}$ are efficient permeation pathways through the film barriers. Thus taking into account the difficulty to improve further the density of 
HWCVD $\mathrm{SiN}_{\mathrm{x}}$ layers grown at $100^{\circ} \mathrm{C}$ through optimized growth conditions [46,48], our focus has turned to the use of hyperthermal particles (in our case rare-gas ions) in order to densify the interfaces or, in other words, to approach as much as possible a lowtemperature silicon nitride surface atomic rearrangement (homoepitaxy). It is known that the optimum low-temperature epitaxial conditions are determined by a delicate balance between the beneficial effects of ion irradiation, such as local relaxation, creation of mobile vacancies, enhanced diffusion..., and the undesirable effects, such as permanent defect formation, lattice damage, sputtering, implantation, etc....[56-58]. This balance can be slightly shifted through control of the ion energy (in the case of low-energy $<100 \mathrm{eV}$ ) and it is believed that an optimum ion energy can be found for low-temperature quasiepitaxial growth of defect-free films.

This window energy range is narrow, thus difficult to control when using RF plasma because the plasma parameters are interdependent. In the following work, only one parameter is changed at a time, all the other parameters being kept fixed.

\subsection{Effect of plasma treatment duration for low energy ions $\left(\mathrm{E}_{\max }=20 \mathrm{eV}\right)$}

For this experiment, the plasma power density is fixed at $350 \mathrm{~mW} / \mathrm{cm}^{2}$ and the working pressure at $6.7 \mathrm{~Pa}$ : the maximum plasma potential is measured as $20 \mathrm{~V}$, which corresponds to the maximum Ar+ bombardment energy of $20 \mathrm{eV}$ (see Table 1). For $\mathrm{SiN}_{\mathrm{x}}$ double layers $(50 \mathrm{~nm}+50 \mathrm{~nm}$ thick), for which only one intermediate plasma treatment has been performed, the WVTR decreases drastically versus treatment duration during the first $8 \mathrm{~min}$ down to $\sim 3 \times 10^{-3} \mathrm{~g} /\left(\mathrm{m}^{2}\right.$ day $)$, and then stabilizes whereas lag-time increases correlatively from 7 to $30 \mathrm{~h}$ [49]. This experiment shows that the improvement of permeation barrier is not immediate due to the low maximum ion energy impacting the $\mathrm{SiN}_{\mathrm{x}}$ surface and that a relatively high ion dose $\left(\sim 5 \times 10^{18} \mathrm{Ar}+\right.$ $\mathrm{cm}^{-2}$ ) has been necessary. If we consider $8 \mathrm{~min}$ as the minimum plasma treatment duration to get a significant improvement of the double layer permeation barrier for $\mathrm{E}_{\max }=20 \mathrm{eV}$, we could expect that by stacking five single layers ( $250 \mathrm{~nm}$ total thickness) separated by four intermediate plasma treatments realized in the same conditions, the quality of such a permeation barrier would be greatly improved. This experiment has been performed: the minimum value found for WVTR was $2 \times 10^{-4} \mathrm{~g} /\left(\mathrm{m}^{2}\right.$ day $)$ whereas the maximum lag-time was $77 \mathrm{~h}$ [50]. Once more, such a multilayer structure is not attaining the required barrier performance for OLEDs.

\subsection{Effect of maximum ion energy for a double layer and a fixed treatment duration $=8$ $\underline{\min }$}

In order to limit the time for experiments, the number of layers has been fixed at two (100 nm total thickness). Playing with the two plasma parameters, i.e. power density andworking pressure, $\mathrm{E}_{\max }$ could vary in the range 10 to $100 \mathrm{eV}$ (see Table 1). Fig. 1 shows that for $\mathrm{E}_{\max }=10 \mathrm{eV}$, no significant effect has been observed for the WVTR and lag-time values, in comparison with the untreated sample. When $\mathrm{E}_{\max }$ increases to 18 , 22, 28 up to $30 \mathrm{eV}$, WVTR decreases almost monotonically whereas lag-time increases correlatively. This corresponds to a continuous improvement of the permeation barrier quality. The minimum for the curve WVTR as a function of $E_{\max }$ is found at $E_{\max }=30$ $\mathrm{eV}$, with a value of $5 \times 10^{-4} \mathrm{~g} /\left(\mathrm{m}^{2}\right.$ day $)$, associated with a maximum lag-time of $50 \mathrm{~h}$. Increasing further $E_{\max }$ up to $38 \mathrm{eV}$, WVTR increases once more to an intermediate level close to that observed for $\mathrm{E}_{\max }=20 \mathrm{eV}$ (see Section 3.1) whilst lag-time decreases 
to $26 \mathrm{~h}$. Finally for $\mathrm{E}_{\max }=100 \mathrm{eV}, \mathrm{WVTR}$ and lag-time are equivalent to the values observed for the untreated sample because the sputtering threshold energy for $\mathrm{SiN}_{\mathrm{x}}$ is greatly exceeded: so severe damage is occurring in the barrier film.

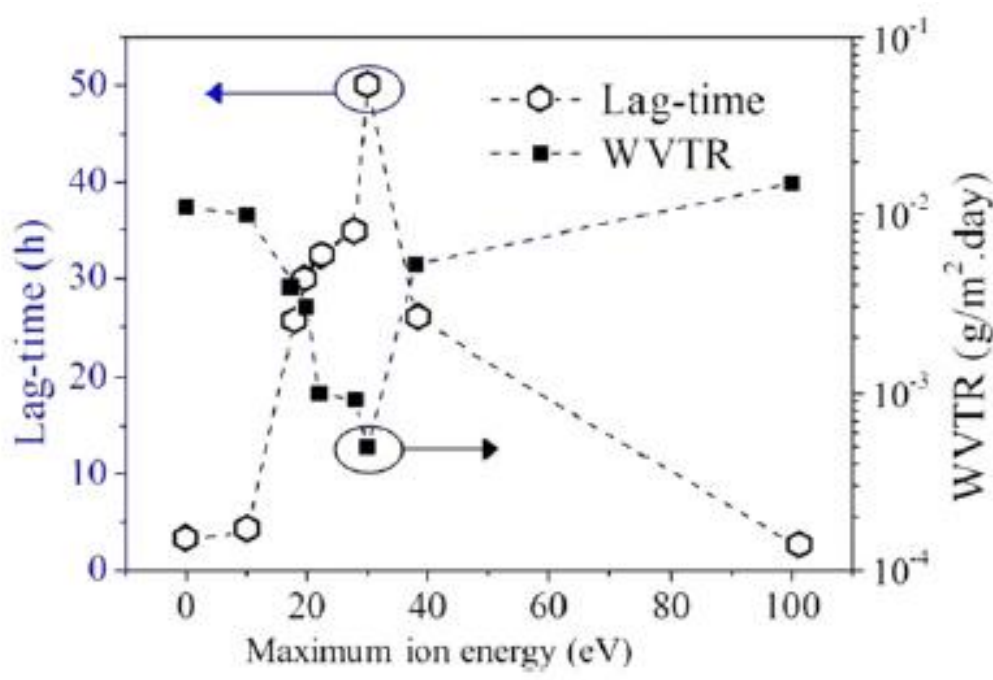

Figure 1- Variation of WVTR and lag-time versus maximum Ar+ energy for a $\operatorname{SiN}_{x}$ double layer barrier of thickness $100 \mathrm{~nm}$ bombarded during $8 \mathrm{~min}$.

\section{$\underline{\text { 3.3. Effect of previously optimized plasma parameters on number of single layers }}$}

Taking into account the results reported in Section 3.2, $\mathrm{E}_{\max }$ is fixed at $30 \mathrm{eV}$ (power density $=400 \mathrm{~mW} / \mathrm{cm}^{2}$, pressure $=3.3 \mathrm{~Pa}$ ), treatment duration at $8 \mathrm{~min}$ whereas the number of stacked layers is increased from two to five. An optical transmittance of $\sim 80 \%$ is observed over the visible range of the spectrum (Fig. 2) for the stack of five layers, which matches the requirements for OLED applications. There is no absorption above $450 \mathrm{~nm}$. In that case, the minimum WVTR is $7 \times 10^{-5} \mathrm{~g} /\left(\mathrm{m}^{2}\right.$ day) whereas the maximum lag-time is $125 \mathrm{~h}$ (Fig. 3), to be compared with $2 \times 10^{-4} \mathrm{~g} /\left(\mathrm{m}^{2}\right.$ day) and $77 \mathrm{~h}$ for the sample of same thickness treated with $E_{\max }=20 \mathrm{eV}$, respectively [50] (see Section 3.1). From these experiments, it is concluded that the lowest WVTR and the highest lag-time are obtained for the five stacked layers separated by the four intermediate plasma treatments and that the quality of the permeation barriers is very sensitive to the maximum Ar+ energy impacting the $\mathrm{SiN}_{\mathrm{x}}$ interfaces. It may also be noted that the average surface roughness of the top $\mathrm{SiN}_{\mathrm{x}}$ layer evolves quite similarly as WVTR as a function of maximum ion energy or number of single layers [59]. 


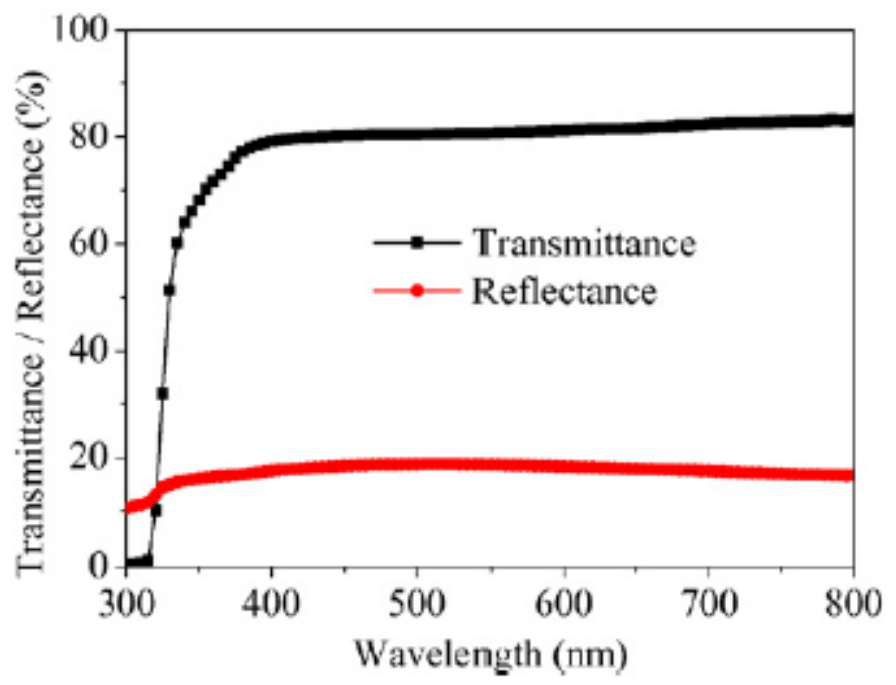

Figure 2 - Reflection and transmission spectra of amultilayer barrier (stack of five $\mathrm{SiN}_{\mathrm{x}}$ single layers) of thickness $250 \mathrm{~nm}$ deposited on PET substrate. For the four intermediate plasma treatments, maximum Ar+ energy is $30 \mathrm{eV}$ and treatment duration is $8 \mathrm{~min}$.

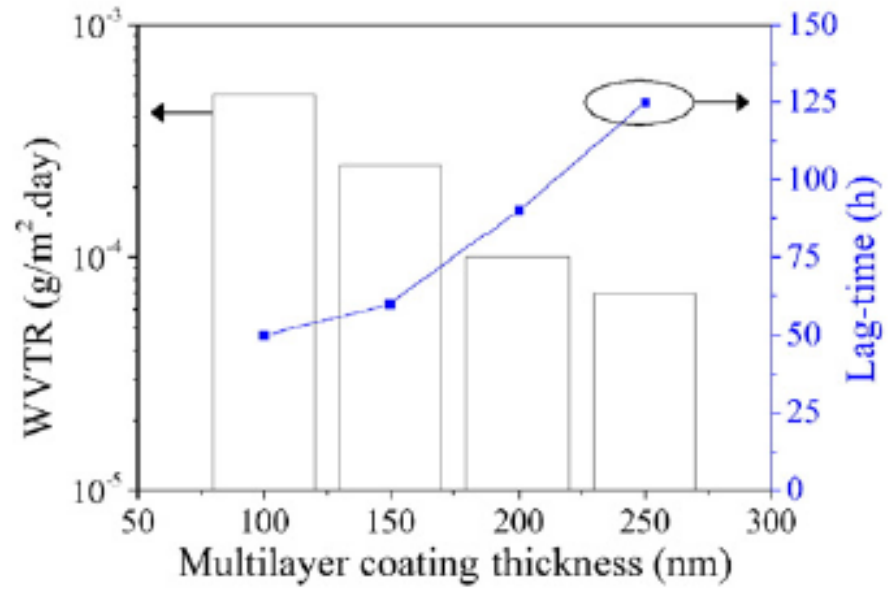

Figure 3 - Variation of WVTR and lag-time versus number of $50 \mathrm{~nm}$ thick $\operatorname{SiN}_{\mathrm{x}}$ single layers. The plasma treatments are: $30 \mathrm{eV}$ maximum Ar+ energy during $8 \mathrm{~min}$.

\subsection{Analysis of untreated and high energy plasma treated SiNx single layers}

In the following, several analysis techniques are used in order to give a physical interpretation of the improvement or degradation of the permeation barriers due to the value of the maximum kinetic energy of the Ar+ impacting the interfaces (or the average energy transfer to the surface $\mathrm{Si}$ and $\mathrm{N}$ atoms). For this purpose three samples composed of $50 \mathrm{~nm}$ thick $\mathrm{SiN}_{\mathrm{x}}$ films deposited by HWCVD on c-Si substrate have been prepared: sample A is as deposited (without plasma treatment), sample B is plasma treated with $\mathrm{E}_{\max }=30 \mathrm{eV}$ during 8 min (optimized plasma conditions of Section 3.2) and sample $\mathrm{C}$ is treated with $\mathrm{E}_{\max }=100 \mathrm{eV}$ during $8 \mathrm{~min}$ (high energy plasma). AFM measurements, not shown (see [59]), exhibit different values for the average surface 
roughness: $2.1 \mathrm{~nm}$ for sample A, $0.7 \mathrm{~nm}$ for sample B (smooth surface) and $2.7 \mathrm{~nm}$ for sample $\mathrm{C}$ (damaged surface probably due to sputtering of atoms).

Fig. 4 shows the FTIR measurements: no significant change is observed between samples $\mathrm{A}$ and $\mathrm{B}$ in the ranges corresponding to $\mathrm{Si}-\mathrm{H}$ bending mode $\left(630 \mathrm{~cm}^{-1}\right), \mathrm{Si}-\mathrm{N}$ stretching mode $\left(860 \mathrm{~cm}^{-1}\right)$ and $\mathrm{Si}-\mathrm{H}_{2}$ stretching mode $\left(2100 \mathrm{~cm}^{-1}\right)$. However an increase of $\mathrm{Si}-\mathrm{H}_{2}$ absorbance band is observed for sample $\mathrm{C}$ compared to sample $\mathrm{A}$, the dihydride species being generally associated with the presence of nanovoids in the material.

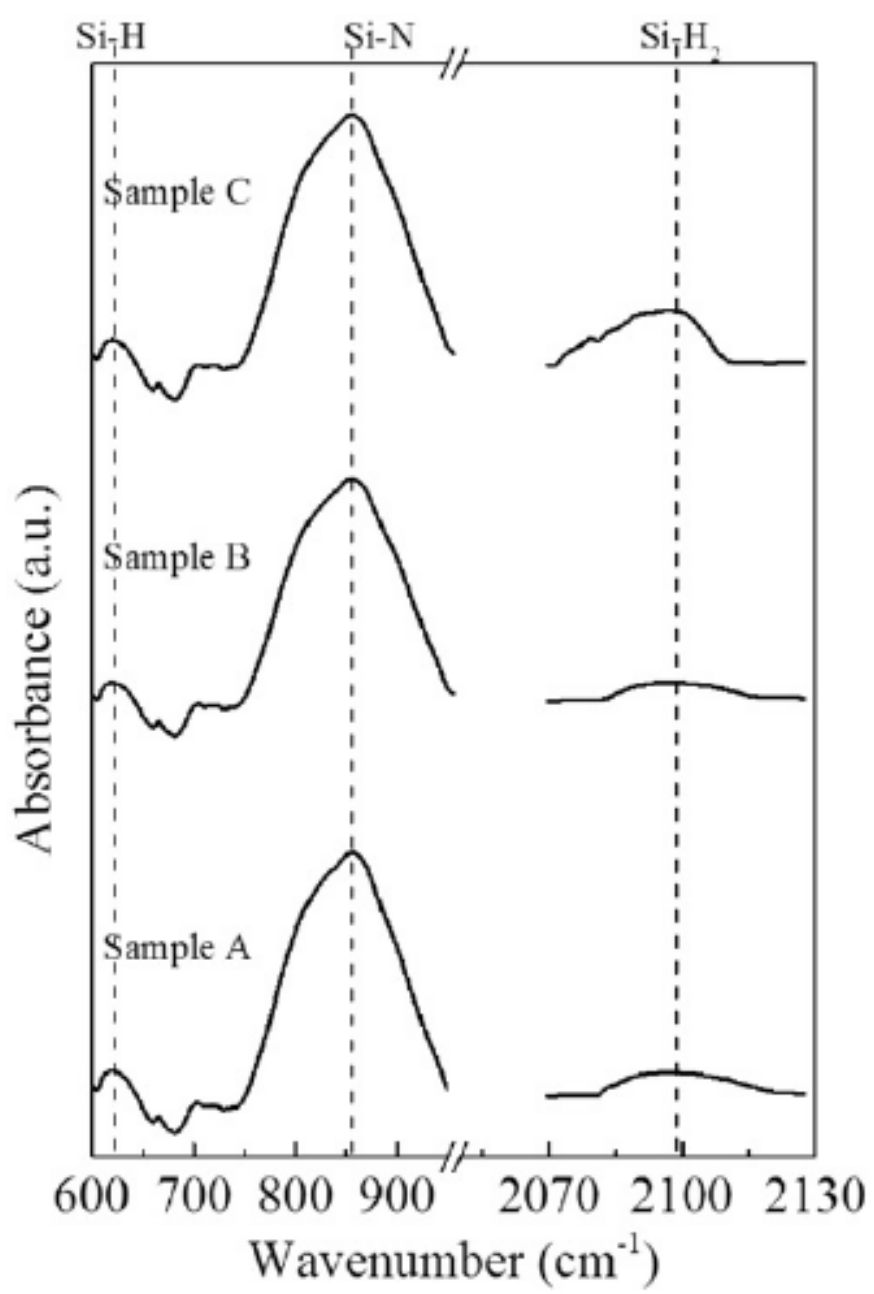

Figure 4- FTIR absorption spectra for three $50 \mathrm{~nm}$ thick SiNx single layers deposited on c-Si substrate: sample A (as deposited), sample B (plasma treatment: $30 \mathrm{eV}$ maximum $\mathrm{Ar}+$ energy during 8min), sample $\mathrm{C}$ (plasma treatment: $100 \mathrm{eV}$ maximum Ar+ energy during $8 \mathrm{~min}$ ).

XRR has been performed on the three samples (Fig. 5): for small q values ( $q=4 \pi \sin \theta / \lambda$ where $\theta$ is the angle of incidence and $\lambda$ is the $X$-ray wavelength), reflectivity signal is higher for sample B (solid square) compared to sample A (open circle), as well as for sample A compared to sample C (solid star). It means that surface roughness for sample $B$ is lower than surface roughness for sample A whereas it is higher for sample $C$ than for sample A, which corresponds to a surface atomic ordering improvement for sample B compared to sample A and a surface degradation for sample $\mathrm{C}$ compared to sample A, 
thus confirming the AFM data. Going further in the fitting of the reflectivity signals using Parratt's model [60], it has been possible to deduce from the XRR data, with sufficient accuracy, the mass density profiles as a function of thickness (Fig. 6). For sample A density is $2.83 \pm 0.04 \mathrm{~g} / \mathrm{cm}^{3}$ throughout the $50 \mathrm{~nm}$ thickness. For sample B the fitting is compatible with two regions of different densities: the bulk region ( $49 \mathrm{~nm}$ thick) with density of $2.83 \mathrm{~g} / \mathrm{cm}^{3}$ and a very thin $(1 \mathrm{~nm})$ surface region with high density of $2.91 \mathrm{~g} / \mathrm{cm}^{3}$ (densified surface region). For sample $\mathrm{C}$ the fitting is compatible with two regions of different densities: the bulk region (43 nm thick) with density of $2.83 \mathrm{~g} / \mathrm{cm}^{3}$ and a thin $(7 \mathrm{~nm})$ surface region with low density of $2.35 \mathrm{~g} / \mathrm{cm}^{3}$ (porous damaged surface region).

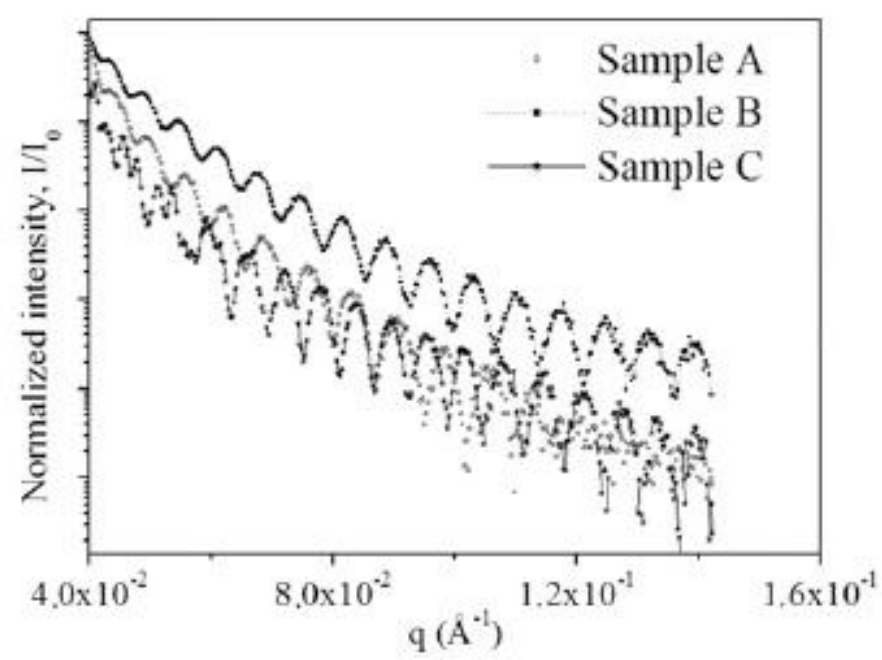

Figure 5 - Normalized X-ray reflectivity signals for three 50 nmthick $\mathrm{SiN}_{\mathrm{x}}$ single layers deposited on c-Si substrate: sample A (open circle, as deposited), sample B (solid square, plasma treatment: $30 \mathrm{eV}$ maximumAr+ energy during 8min), sample $\mathrm{C}$ (solid star, plasma treatment: $100 \mathrm{eV}$ maximum Ar+ energy during $8 \mathrm{~min}$ ). 


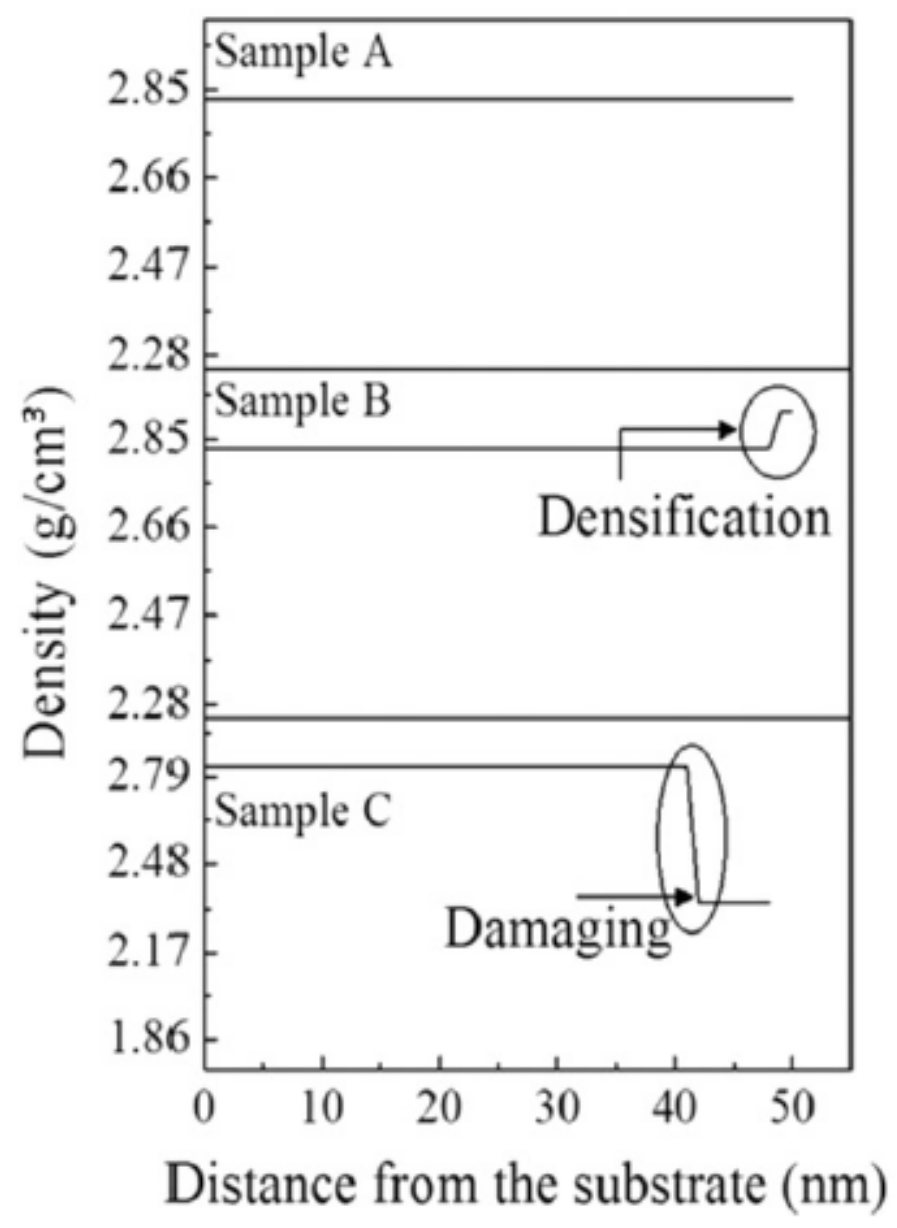

Figure 6 - Density profiles for the three $50 \mathrm{~nm}$ thick $\mathrm{SiN}_{\mathrm{x}}$ single layers deposited on c-Si substrate deduced from the normalized X-ray reflectivity signals (Fig. 5) using Parratt'smodel [60].

Fig. 7 shows the GD-OES profiles of the different elements ( $\mathrm{Si}, \mathrm{N}, \mathrm{H}, \mathrm{O}$ and $\mathrm{Ar}$ ) for the three samples. When these results are compared to those issued from XPS for the same samples, not shown (see [59]), it is observed that $\mathrm{Si}$ and $\mathrm{N}$ signals are unchanged whatever the sample. On the contrary, on the surface, there is a slightly lower O signal for sample $\mathrm{B}$ and a larger $\mathrm{O}$ signal for sample $\mathrm{C}$ as compared to sample A. The same trend is observed for $\mathrm{H}$ signal using GD-OES only. Finally for sample $\mathrm{C}$, no Ar signal is observed by XPS whilst a small Ar signal is observed using GD-OES. 


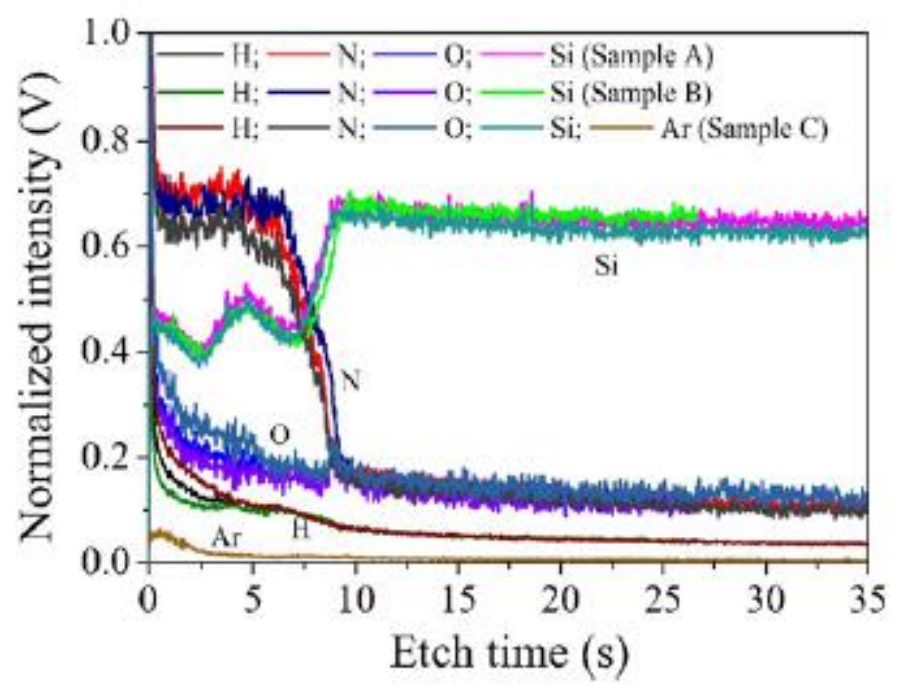

Figure 7 - GD-OES depth profiles of $\mathrm{H}, \mathrm{N}, \mathrm{O}, \mathrm{Si}$ and Ar elements for three $50 \mathrm{~nm}$ thick $\mathrm{SiN}_{\mathrm{x}}$ single layers deposited on c-Si substrate: sample A (as deposited), sample B (plasma treatment: $30 \mathrm{eV}$ maximum Ar+ energy during $8 \mathrm{~min}$ ), sample $\mathrm{C}$ (plasma treatment: $100 \mathrm{eV}$ maximum Ar+ energy during $8 \mathrm{~min}$ ) [59].

\subsection{Tentative interpretation of $\mathrm{E}_{\max }$ effect on permeation barrier performances}

The loss of energy by a charged particle is caused by the interaction of the electric field associated with the moving charge and the one generated by the electronic (and nuclear) structure of the target medium. This process is referred to as energy-loss process and allows the dissipation of energy inside the medium itself. Using the sequential binary collision approximation between an incoming ion of energy $\mathrm{E}$ and target atoms, the damage energy transferred into the target surface and the underlying bulk can be estimated [61-63]. This deposited energy per ion is governed by the nuclear and electronic stopping powers, which are caused by the elastic collision of incident ion with the surface atoms and the inelastic scattering of ion by the electrons in the solid target, respectively. At low Ar ion energy b100 eV, which means at low ion velocities $<2 \times 10^{4} \mathrm{~m} / \mathrm{s}$, the main energy loss mechanism is through elastic collisions with atoms at the surface, known as nuclear collisions, associated with a statistical distance traveled by the ions before coming to rest in the nm range along a plane perpendicular to the axis of incidence: the value of this perpendicular range depends critically on the ion energy. It has been shown that, in this low-energy range, it is possible to generate atomic displacements in surface layers whilst avoiding the occurrence of displacement damage in the underlying bulk material, which is the basis of ion beam assisted epitaxy [61-63]. For Ar+ bombardment of a Si target, the atomic threshold displacement energy, defined as the minimum kinetic energy needed for a target atom to be permanently displaced from its regular site to a defect position, thus creating a Frenkel pair (vacancy-interstitial pair) in the solid, has been reported to be $15-18 \mathrm{eV}$ [63-65]. It is important to note that threshold displacement energy for $\mathrm{Si}$ is much higher than surface binding energy of $\mathrm{Si}$ (4.7 eV/atom) [65]. The reason for this large difference is attributed to the fact that for very low energy $(\sim 10 \mathrm{eV})$ ions, the binary collision approximation is no more valid, so the ion-solid interaction should be described by many-body theory: since many atoms in 
a small volume surrounding one specific atom share the projectile's energy in the slowing down process, the actual energy transferred to every atom is much lower than the energy required for displacing one atom and hence heat spikes (thermal spikes) are expected to occur $[66,67]$.

To interpret the results presented in Sections 3.1 to 3.4, we have made extensive use of a previous study that involved direct ion beam deposition of ${ }^{28} \mathrm{Si}+$ ions for homoepitaxial film growth on c-Si over the low ion energy range of $8-80 \mathrm{eV}$ and in the low-temperature range of $40-500^{\circ} \mathrm{C}$ [58]. We take advantage of the analogy between the phase diagram substrate temperature versus $\mathrm{Si}+$ ion energy proving the existence of $\mathrm{Si}$ ion-beam homoepitaxy and the curve WVTR of $\mathrm{SiN}_{\mathrm{x}}$ barrier layer versus maximum Ar+ ion energy (Fig. 1) proving the improvement of $\mathrm{SiN}_{\mathrm{x}}$ barrier layer, even though the initial conditions for these two experiments are different: epitaxial growth on c-Si substrate in one case, surface atomic rearrangement of $\mathrm{a}-\mathrm{SiN}_{\mathrm{x}}$ layer in the other case. The techniques used for both studies are also different: in situ reflection high-energy electron diffraction and ex situ Rutherford backscattering spectroscopy (RBS) for assessing crystalline structure of Si films for Si homoepitaxy [58] and ex situ FTIR, XRR, GD-OES, XPS and WVTR for assessing improved $\mathrm{SiN}_{\mathrm{x}}$ barrier films in the present study. Intuitively, it may be argued that surface atomic rearrangement of Si and $\mathrm{N}$ atoms at the interfaces should be tiny, of the order of $0.1-0.2 \mathrm{~nm}$, in comparison with the critical average atomic displacement of $0.5 \mathrm{~nm}$ explaining the amorphization of c-Si induced by ion implantation [68]. Thus we assume that the optimum ion energy window around $20 \mathrm{eV}$ at $160^{\circ} \mathrm{C}$ for achieving silicon epitaxial growth has the same physical origin as the optimum Ar+ maximum kinetic energy $\mathrm{E}_{\max }=30 \mathrm{eV}$ at $100^{\circ} \mathrm{C}$ for improving $\mathrm{SiN}_{\mathrm{x}}$ barrier properties. Taking into account the energy transfer ET from incoming $\mathrm{Ar}$ ion to $\mathrm{Si}$ target atom belonging to the $\mathrm{SiN}_{\mathrm{x}}$ network (Section 2.2), this assumed equivalence sets the ratio of the Ar+ average energy value to $\mathrm{E}_{\max }$. This ratio is equal to 0.688 .

Finally the last data concern the sputtering threshold energy for Si bombarded by normally incident Ar ions, assessed as $~ 50 \mathrm{eV}[64,65]$.

If we consider Fig. 1, for $\mathrm{E}_{\max }=20 \mathrm{eV}$ corresponding to an average energy transfer from incoming $\mathrm{Ar}+$ to $\mathrm{Si}$ atoms in the $\mathrm{SiN}_{\mathrm{x}}$ target of $13.3 \mathrm{eV}$, i.e. below the minimum atomic threshold displacement energy of $15 \mathrm{eV}$ [63-65], the probability for displaced atoms at the interface is not significant: however taking into account the temperature of the substrate during the plasma process $\left(100^{\circ} \mathrm{C}\right)$ and the high ion dose $\left(\sim 5 \times 10^{18} \mathrm{Ar}+\right.$ $\mathrm{cm}^{-2}$ ), heat spikes (thermal spikes) may occur with locally a majority of atoms temporarily in motion [66], leading to a partial rearrangement of the $\mathrm{Si}$ atoms at the interface. This partial atomic rearrangement explains the intermediate values obtained for both WVTR and lag-time. When $\mathrm{E}_{\max }$ increases to $22 \mathrm{eV}$, corresponding to an average energy transfer of $14.7 \mathrm{eV}$, very near the minimum threshold energy, the probability for displaced atoms increases rapidly and simultaneously with the occurrence of thermal spikes, WVTR decreases frankly whereas lag-time increases. Obviously for $\mathrm{E}_{\max }=30 \mathrm{eV}$ (sample $\mathrm{B}$ ), which corresponds to an average energy transfer equal to or slightly higher than the average threshold displacement energy for $\mathrm{Si}(\sim 20$ $\mathrm{eV})$, Frenkel defects are created in the interface layer together with induced strain, resulting in localized regions in which the defects are mobile [58]. Taking also into account the constant temperature $\left(100^{\circ} \mathrm{C}\right)$ during the plasma process, when the equilibrium concentration of these mobile defects becomes sufficient, local atomic rearrangements take place in the interface layer leading to a densification of this interface, what has been observed on the surface of sample B (Fig. 6), as deduced from 
XRR experiment. It may be noted that densification of vapor deposited $\mathrm{ZrO}_{2}$ film under low-energy Ar+ and O+ bombardments has also been observed [69,70]. Thus it is logical, in such conditions, that barrier permeation is improved: WVTR reaches a minimum whereas lag-time reaches a maximum (Fig. 1). As ion energy continues to increase above the threshold displacement energy, for example when $E_{\max }=38 \mathrm{eV}$, corresponding to an average energy transfer of $25.3 \mathrm{eV}$, the collision cascades become more and more numerous, producing defect clusters, which causes a beginning of permanent damage in the interface layer. Thus an increase of WVTR correlated with a decrease of lag-time is observed (Fig. 1). Finally when $\mathrm{E}_{\max }=100 \mathrm{eV}$ (sample C), corresponding to an average energy transfer of $66.7 \mathrm{eV}$, i.e. above the sputtering threshold energy for $\mathrm{Si}(\sim 50 \mathrm{eV})[64,65]$, defect density increases drastically, sputtering of $\mathrm{Si}$ and $\mathrm{N}$ atoms occurs, both effects being compatible with the presence of nanovoids observed in FTIR spectra (Fig. 4) or of pores of size $\sim 1 \mathrm{~nm}$, with a large increase of $\mathrm{O}$ content observed by XPS and GD-OES (Fig. 7). These effects lead to a drastic decrease of surface density, as has been observed on the surface of sample C (Fig. 6), as deduced from XRR experiment. Lastly, implanted Ar has been detected by GD-OES (Fig. 7) with a projected range of $3.3 \mathrm{~nm}$, a straggling of $1.5 \mathrm{~nm}$ and an amount $<0.1$ at.\% (below the detection limit of XPS), which is in good agreement with Lau et al. [71] who observed, using XPS and RBS, an amount of $3 \times 10^{14} \mathrm{Ar} \mathrm{cm}^{-2}$ implanted $2 \mathrm{~nm}$ below the Si surface and a straggling of $1 \mathrm{~nm}$ for $100 \mathrm{eV}$ Ar ions bombarding c-Si with a fluence of $2 \times 1017 \mathrm{Ar}+\mathrm{cm}-2$. In short, when $\mathrm{E}_{\max }=100 \mathrm{eV}$ for which the $\mathrm{SiN}_{\mathrm{x}}$ interface layer is severely damaged, it is coherent to observe no beneficial effect issued from the plasma treatment. So WVTR and lag-time values are equivalent to those measured for the untreated sample A (see Fig. 1).

\section{Conclusions}

Permeation barrier stacks for the encapsulation of organic electronics (OLEDs or organic photovoltaics) have been developed that combine inorganic $\mathrm{SiN}_{\mathrm{x}} / \mathrm{SiN}_{\mathrm{x}}$ multilayers grown by HWCVD at low-temperature $\left(\sim 100^{\circ} \mathrm{C}\right)$ with an intermediate $\mathrm{Ar}$ plasma treatment between two successive $50 \mathrm{~nm}$ thick single layers. The aim was to develop an alternative simple way for making permeation barriers, based on multilayers made of one inorganic material, compared with the usual approach based on multilayers made of alternating inorganic $\mathrm{Al}_{2} \mathrm{O}_{3} / \mathrm{SiO}_{2}, \mathrm{Al}_{2} \mathrm{O}_{3} / \mathrm{ZrO} 2$...bilayers grown by ALD. The idea of using ion bombardment was that, with low energy ions $\sim 50 \mathrm{eV}$ it is possible to improve surface layers at low-temperature ( $\mathrm{Si}$ ion-beam epitaxy for instance), thus avoiding large scale interdiffusion resulting from high temperature processing. In the present work, maximum Ar+ energy has been adjusted through the control of plasma power density and gas pressure to get a minimum of WVTR and a maximum of lagtime. A narrow window for maximum ion energy has been found around $30 \mathrm{eV}$, leading to a minimum of WVTR $\left(7 \times 10^{-5} \mathrm{~g} /\left(\mathrm{m}^{2}\right.\right.$ day $\left.)\right)$ associated with a maximum of lag-time $(125 \mathrm{~h})$ for a multilayer composed of five $\mathrm{SiN}_{\mathrm{x}}$ single layers separated by four intermediate plasma treatments. An additional study based on the choice of two specific $E_{\max }$ values $(30 \mathrm{eV}$ and $100 \mathrm{eV}$ ) allowed to confirm, with the help of several surface analytical techniques, that $\mathrm{SiN}_{\mathrm{x}}$ surface layer is densified for $\mathrm{E}_{\max }=30 \mathrm{eV}$ whilst this surface is severely damaged for $\mathrm{E}_{\max }=100 \mathrm{eV}$. The interpretation of all these results has been made using the analogy with low-energy ion beam homoepitaxy of Si. Taking into account the temperature of the substrate during the plasma process $\left(\sim 100^{\circ} \mathrm{C}\right)$, for an $\mathrm{Ar}$ flux with maximum ion energy of $30 \mathrm{eV}$ impacting the $\mathrm{SiN}_{\mathrm{x}}$ interface, corresponding to 
an average energy transfer to the surface $\mathrm{Si}$ atoms of $20 \mathrm{eV}$ (the average atomic threshold displacement energy for $\mathrm{Si}$ ), an atomic rearrangement of the interface takes place leading to a densification of this interface: the permeation barrier is improved as confirmed by a decrease of WVTR and an increase of lag-time. On the contrary, for a maximum ion energy of $100 \mathrm{eV}$, corresponding to an average energy transfer of 66.7 $\mathrm{eV}$, i.e. above the sputtering threshold energy for $\mathrm{Si}(\sim 50 \mathrm{eV}), \mathrm{N}$ and $\mathrm{Si}$ atoms are sputtered whilst Ar atoms are incorporated $3 \mathrm{~nm}$ below the surface, probably inducing pores of size larger than $1 \mathrm{~nm}: \mathrm{SiN}_{\mathrm{x}}$ interfaces are greatly deteriorated, so there is no beneficial effect issued from the Ar plasma treatment. To further improve the permeation barriers realized using the present approach, effort should be focused in scanning the narrow energy window for the average energy transfer around $20 \mathrm{eV}$, by increasing this energy with a small increment. Once the optimum of energy transfer is found, a new minimum for plasma treatment duration should be searched. Finally this work has given the experimental proof that using low energy ion bombardment, it is possible to modify sharply inorganic interfaces with a reduced thermal budget. Such an approach can be useful for specific applications of organic electronic devices.

\section{Acknowledgements}

The authors are grateful to Dr. R. Cortes (PMC, Ecole Polytechnique) for XRR analysis, to Dr. P. Chapon (HORIBA Jobin Yvon) for GD-OES analysis and Dr. J. Leroy (CEA Saclay) for XPS analysis. This work was partly supported by the PICS (FrenchPortuguese) project No. 5336. One of the authors (S.M.) acknowledges Direction des Relations Extérieures of Ecole Polytechnique for financial support.

\section{References}

[1] S.Wagner, H. Gleskova, I.C. Cheng,M. Wu, Silicon for thin-film transistors, Thin Solid Films 430 (2003) 15.

[2] J.S. Lewis,M.S. Weaver, Thin-film permeation-barrier technology for flexible organic light-emitting devices, IEEE J. Sel. Top. Quantum Electron. 10 (2004) 45.

[3] Y.F. Liew, H. Aziz, N.X. Hu, H.S.O. Chan, G. Xu, Z. Popovic, Investigation of the sites of dark spots in organic light-emitting devices, Appl. Phys. Lett. 77 (2000) 2650.

[4] M.S. Weaver, L.A. Michalski, K. Rajan, M.A. Rothman, J.A. Silvernail, J.J. Brown, P.E. Burrows, G.L. Graff, M.E. Gross, P.M. Martin, M. Hall, E. Mast, C. Bonham, W. Bennett, M. Zumhoff, Organic light-emitting devices with extended operating lifetimes on plastic substrates, Appl. Phys. Lett. 81 (2002) 2929.

[5] P.E. Burrows, G.L. Graff, M.E. Gross, P.M. Martin, M. Hall, E. Mast, C. Bonham, W. Bennett, L. Michalski, M.S. Weaver, J.J. Brown, D. Fogarty, L.S. Sapochak, Gas permeation and lifetime tests on polymer-based barrier coatings, Proc. SPIE 4105 (2001) 75.

[6] P.E. Burrows, V. Bulovic, S.R. Forrest, L.S. Sapochak, D.M. McCarty, M.E. Thompson, Reliability and degradation of organic light emitting devices, Appl. Phys. Lett. 65 (1994) 2922.

[7] J.H. Lee, C.I. Wu, S.W. Liu, C.A. Huang, Y. Chang, Mixed host organic lightemitting devices with low driving voltage and long lifetime, Appl. Phys. Lett. 86 (2005) 103506.

[8] Y. Leterrier, Durability of nanosized oxygen-barrier coatings on polymers, Prog. Mater. Sci. 48 (2003) 1. 
[9] A. Heya, T. Minamikawa, T. Niki, S. Minami, A. Masuda, H. Umemoto, N. Matsuo, H. Matsumura, Cat-CVD SiN passivation films for OLEDs and packaging, Thin Solid Films 516 (2008) 553.

[10] J. Ubrig, M. Bedjaoui, S. Martin, S. Cros, J.E. Bourée, Deposition of high permeation barrier films by plasma-enhanced chemical vapor deposition for organic solar cells, Proc. 23rd European Photovoltaic Solar Energy Conference and Exhibition 2008, p. 712.

[11] J. Fahlteich, S. Mogck, T. Wanski, N. Schiller, S. Amberg-Schwab, U. Weber, O. Miesbauer, E. Kücüpinar-Niarchos, K. Noller, C. Boeffel, The role of defects in singleand multi-layer barriers for flexible electronics, 57th Ann. Tech. Conf. Proceedings of the Society of Vacuum Coaters 2014, p. 36.

[12] M.D. Groner, S.M. George, R.S.McLean, P.F. Carcia, Gas diffusion barriers on polymers using Al2O3 atomic layer deposition, Appl. Phys. Lett. 88 (2006) 051907.

[13] E. Langereis, M. Creatore, S.B.S. Heil,M.C.M. van de Sanden,W.M.M. Kessels, Plasma assisted atomic layer deposition of $\mathrm{Al} 2 \mathrm{O} 3$ moisture permeation barriers on polymers, Appl. Phys. Lett. 89 (2006) 081915.

[14] M. Leskelä, M. Ritala, Atomic layer deposition (ALD): from precursors to thin film structures, Thin Solid Films 409 (2002) 138.

[15] W. Keuning, P. van deWeijer, H. Lifka,W.M.M. Kessels,M. Creatore, Cathode encapsulation of organic light emitting diodes by atomic layer deposited Al2O3 films and Al2O3/a-SiNx:H stacks, J. Vac. Sci. Technol. A 30 (2012), 01A131.

[16] A. Perrotta, E.R.J. van Beekum, G. Aresta, A. Jagia, W. Keuning, R.M.C.M. van de Sanden, E.W.M.M. Kessels, M. Creatore, On the role of nanoporosity in controlling the performance of moisture permeation barrier layers, Microporous Mesoporous Mater. 188 (2014) 163.

[17] D.G. Shaw, M.G. Langlois, Use of vapor deposited acrylate coatings to improve the barrier properties ofmetallized film, 37th Ann. Tech. Conf. Proceedings of the Society of Vacuum Coaters 1994, p. 240.

[18] G.L. Graff, R.E. Williford, P.E. Burrows, Mechanisms of vapor permeation through multilayer barrier films: lag time versus equilibrium permeation, J. Appl. Phys. 96 (2004) 1840.

[19] A.G. Erlat, B.M. Henry, C.R.M. Grovenor, A.G.D. Briggs, R.J. Chater, Y. Tsukahara, Mechanism of water vapor transport through PET/AlOxNy gas barrier films, J. Phys. Chem. B 108 (2004) 883.

[20] C. Charton, N. Schiller,M. Fahland, A. Holländer, A.Wedel, K. Noller, Development of high barrier films on flexible polymer substrates, Thin Solid Films 502 (2006) 99.

[21] T.N. Chen, D.S. Wuu, C.C. Wu, C.C. Chiang, Y.P. Chen, R.H. Horng, Improvements of permeation barrier coatings using encapsulated parylene interlayers for flexible electronic applications, Plasma Process. Polym. 4 (2007) 180.

[22] D.S. Wuu, T.N. Chen, E. Lay, C.H. Liu, C.H. Chang, H.F. Wei, L.Y. Jiang, H.U. Lee, Y.Y. Chang, Transparent barrier coatings on high temperature resisting polymer substrates for flexible electronic applications, J. Electrochem. Soc. 157 (2010) C47.

[23] F.L. Wong, M.K. Fung, S.L. Tao, S.L. Lai, W.M. Tsang, K.H. Kong, W.M. Choy, C.S. Lee, S.T. Lee, Long-lifetime thin-film encapsulated organic light-emitting diodes, J. Appl. Phys. 104 (2008) 014509.

[24] S.H. Jen, J.A. Bertrand, S.M. George, Critical tensile and compressive strains for cracking of Al2O3 films grown by atomic layer deposition, J. Appl. Phys. 109 (2011) 084305 . 
[25] S.H. Jen, B.H. Lee, S.M. George, R.S.McLean, P.F. Carcia, Critical tensive strain and water vapor transmission rate for nanolaminate films grown using $\mathrm{Al} 2 \mathrm{O} 3$ atomic layer deposition and alucone molecular layer deposition, Appl. Phys. Lett. 101 (2012) 234103.

[26] A.M. Coclite, G. Ozaydin-Ince, F. Palumbo, A. Milella, K.K. Gleason, Singlechamber deposition of multilayer barriers by plasma enhanced and initiated chemical vapor deposition of organosilicones, Plasma Process. Polym. 7 (2010) 561.

[27] B.J. Kim, D.H. Kim, S.Y. Kang, S.D. Ahn, S.G. Im, A thin film encapsulation layer fabricated via initiated chemical vapor deposition and atomic layer deposition, J. Appl. Polym. Sci. 131 (2014) 40974.

[28] D. Spee, K. van derWerf, J. Rath, R. Schropp, Excellent organic/inorganic transparent thin film moisture barrier entirely made by hot wire CVD at $100^{\circ} \mathrm{C}$, Phys. Status Solidi (RRL) 6 (2012) 151.

[29] D.A. Spee, J.K. Rath, R.E.I. Schropp, Using hotwire and initiated chemical vapor deposition for gas barrier thin film encapsulation, Thin Solid Films 575 (2015) 67.

[30] H. Nakayama, M. Ito, Super H2O-barrier film using Cat-CVD (HWCVD)-grown SiCN for film-based electronics, Thin Solid Films 519 (2011) 4483.

[31] C.Hossbach, F.Nehm, A. Singh, H. Klumbies,D. Fisher, C. Richter, U. Schroeder,M. Albert, L.Müller-Meskamp, K. Leo, T. Mikolajick, J.W. Bartha, Integration ofmolecular-layerdeposited aluminum alkoxide interlayers into inorganic nanolaminate barriers for encapsulation of organic electronics with improved stress resistance, J. Vac. Sci. Technol. A 33 (2015), 01 A119.

[32] S.W. Seo, H. Chae, S.J. Seo, H.K. Chung, S.M. Cho, Extremely bendable thin-film encapsulation of organic light-emitting diodes, Appl. Phys. Lett. 102 (2013) 161908.

[33] S.W. Seo, E. Jung, S.J. Seo, H. Chae, H.K. Chung, S.M. Cho, Toward fully flexible multilayer moisture-barriers for organic light-emitting diodes, J. Appl. Phys. 114 (2013) 143505.

[34] W.E. Tenhaeff, K.K. Gleason, Initiated and oxidative chemical vapor deposition of polymeric thin films: iCVD and oCVD, Adv. Funct. Mater. 18 (2008) 979.

[35] S.M. George, Atomic layer deposition: an overview, Chem. Rev. 110 (2010) 111.

[36] R. Grover, R. Srivastava, O. Rana, D.S. Mehta, M.N. Kamalasanan, New organic thinfilm encapsulation for organic light emitting diodes, J. Enc. Ads. Sci. 1 (2011) 23.

[37] P.F. Carcia, R.S. McLean, M.H. Reilly, M.D. Groner, S.M. George, Ca test of $\mathrm{Al} 2 \mathrm{O} 3$ gas diffusion barriers grown by atomic layer deposition on polymers, Appl. Phys. Lett. 89 (2006) 031915.

[38] A.A. Dameron, S.D. Davidson, B.B. Burton, P.F. Carcia, R.S. McLean, S.M. George, Gas diffusion barriers on polymers using multilayers fabricated by $\mathrm{A} 12 \mathrm{O} 3$ and rapid SiO2 atomic layer deposition, J. Phys. Chem. C 112 (2008) 4573.

[39] J. Meyer, D. Schneidenbach, T. Winkler, S. Hamwi, T. Weimann, P. Hinze, S. Ammermann, H.H. Johannes, T. Riedl,W. Kowalsky, Reliable thin film encapsulation for organic light emitting diodes grown by low-temperature atomic layer deposition, Appl. Phys. Lett. 94 (2009) 233305.

[40] J. Meyer, H. Schmidt, W. Kowalsky, T. Riedl, A. Kahn, The origin of low water vapor transmission rates through $\mathrm{Al} 2 \mathrm{O} 3 / \mathrm{ZrO} 2$ nanolaminate gas-diffusion barriers grown by atomic layer deposition, Appl. Phys. Lett. 96 (2010) 243308.

[41] P.F. Carcia, R.S.McLean, Z.G. Li,M.H. Reilly,W.J. Marshall, Permeability and corrosion in $\mathrm{ZrO} 2 / \mathrm{A} 12 \mathrm{O} 3$ nanolaminate and $\mathrm{Al} 2 \mathrm{O} 3$ thin films grown by atomic layer deposition on polymers, J. Vac. Sci. Technol. A 30 (2012), 041515. 
[42] P.F. Carcia, R.S. McLean, M.D. Groner, A.A. Dameron, S.M. George, Gas diffusion ultrabarriers on polymer substrates using $\mathrm{Al} 2 \mathrm{O} 3$ atomic layer deposition and SiN plasma-enhanced chemical vapor deposition, J. Appl. Phys. 106 (2009) 023533.

[43] Y. Liao, F. Yu, L. Long, B.Wei, L. Lu, J. Zhang, Low-cost and reliable thin film encapsulation for organic light emitting diodes using magnesium fluoride and zinc sulfide, Thin Solid Films 519 (2011) 2344.

[44] B.H. Choi, J.H. Lee, Long-term stable water vapor permeation barrier properties of $\mathrm{SiN} / \mathrm{SiCN} / \mathrm{SiN}$ nanolaminated multilayers grown by plasma-enhanced chemical vapor deposition at extremely low pressures, Appl. Phys. Lett. 105 (2014) 053302.

[45] Y. Ogawa, K. Ohdaira, T. Oyaidu, H. Matsumura, Protection of organic lightemitting diodes over 50000 hours by Cat-CVD SiNx/SiOxNy stacked thin films, Thin Solid Films 516 (2008) 611.

[46] P. Alpuim, L.M. Gonçalves, E.S.Marins, T.M.R. Viseu, S. Ferdov, J.E. Bourée, Deposition of silicon nitride thin films by hot-wire CVD at $100^{\circ} \mathrm{C}$ and $250^{\circ} \mathrm{C}^{\circ}$, Thin Solid Films 517 (2009) 3503.

[47] J.E. Bourée, S.R. Jadkar, S. Kasouit, R. Vanderhaghen, Transport in microcrystalline silicon thin films deposited at low temperature by hot-wire chemical vapor deposition, Thin Solid Films 501 (2006) 133.

[48] S. Majee, M.F. Cerqueira, D. Tondelier, J.C. Vanel, B. Geffroy, Y. Bonnassieux, P. Alpuim, J.E. Bourée, Permeation barrier performance of hot wire-CVD grown siliconnitride films treated by argon plasma, Thin Solid Films 575 (2015) 72.

[49] S. Majee, M.F. Cerqueira, D. Tondelier, B. Geffroy, Y. Bonnassieux, P. Alpuim, J.E. Bourée, The effect of argon plasma treatment on the permeation barrier properties of silicon nitride layers, Surf. Coat. Technol. 235 (2013) 361.

[50] S. Majee, M.F. Cerqueira, D. Tondelier, B. Geffroy, Y. Bonnassieux, P. Alpuim, J.E. Bourée, Influence of lowenergy argon plasma treatment on themoisture barrier performance of hot wire-CVD grown SiNx multilayers, Jpn. J. Appl. Phys. 53 (2014), 05FM05.

[51] K. Köhler, D.E. Horne, J.W. Coburn, Frequency dependence of ion bombardment of grounded surfaces in rf argon glow discharges in a planar system, J. Appl. Phys. 58 (1985) 3350.

[52] E.A. Edelberg, A. Perry, N. Benjamin, E.S. Aydil, Compact floating ion energy analyser formeasuring energy distributions of ions bombarding radio-frequency biased electrode surfaces, Rev. Sci. Instrum. 70 (1999) 2689.

[53] R. Paetzold, A. Winnacker, D. Henseler, V. Cesari, K. Heuser, Permeation rate measurements by electrical analysis of calcium corrosion, Rev. Sci. Instrum. 74 (2003) 5147.

[54] J.H. Choi, Y.M. Kim, Y.W. Park, J.W. Huh, B.K. Ju, I.S. Kim, H.N. Hwang, Evaluation of gas permeation barrier properties using electrical measurements of calcium degradation, Rev. Sci. Instrum. 78 (2007) 064701.

[55] S. Schubert, H. Klumbies, L. Müller-Meskamp, K. Leo, Electrical calciumtest formoisture barrier evaluation for organic devices, Rev. Sci. Instrum. 82 (2011) 094101. [56] J.S. Williams, R.G. Elliman, W.L. Brown, T.E. Seidel, Dominant influence of beaminduced interface rearrangement on solid-phase epitaxial crystallization of amorphous silicon, Phys. Rev. Lett. 55 (1985) 1482.

[57] G. Lulli, P.G. Merli, Comparison of results and models of solid-phase epitaxial growth of implanted Si layers induced by electron- and ion-beam irradiation, Phys. Rev. B 47 (1993) 14023.

[58] J.W. Rabalais, A.H. Al-Bayati, K.J. Boyd, D. Marton, J. Kulik, Z. Zhang, W.K. Chu, Ionenergy effects in silicon ion-beam epitaxy, Phys. Rev. B 53 (1996) 10781. 
[59] S. Majee, PhD thesis. Ecole polytechnique, France, Development of efficient permeation barriers based on hot-wire CVD grown silicon nitride multilayers for organic devices deposited on flexible substrates, 2014 https://pastel.archivesouvertes.fr/pastel- 01067937/document.

[60] L.G. Parratt, Surface studies of solids by total reflection of X-rays, Phys. Rev. 95 (1954) 359.

[61] D.K. Brice, J.Y. Tsao, S.T. Picraux, Partitioning of ion-induced surface and bulk displacements, Nucl. Instrum. Methods Phys. Res. B 44 (1989) 68.

[62] Z.Q. Ma, B.X. Liu, Enhancement of atomic rearrangement in top surface layers by low energy ions, Chin. Phys. Lett. 15 (1998) 668.

[63] Z.Q. Ma, Y.F. Zheng, B.X. Liu, Ion-induced surface and bulk displacement threshold for epitaxial growth, Phys. Status Solidi A 169 (1998) 239.

[64] E. Hotston, Threshold energies for sputtering, Nucl. Fusion 15 (1975) 544.

[65] K. Wittmaack, Analytical description of the sputtering yield of silicon bombarded with normally incident ions, Phys. Rev. B 68 (2003) 235211.

[66] P. Sigmund, Energy density and time constant of heavy-ion-induced elasticcollision spikes in solids, Appl. Phys. Lett. 25 (1974) 169.

[67] A.H. Al-Bayati, K.G. Orrman-Rossiter, R. Badheka, D.G. Armour, Radiation damage in silicon (001) due to low energy (60-510 eV) argon ion bombardment, Surf. Sci. 237 (1990) 213.

[68] L.J. Garcia, Y. Kawamura, M. Uematsu, J.M. Hernandez-Mangas, K.M. Itoh, Monte Carlo simulation of silicon atomic displacement and amorphization induced by ion implantation, J. Appl. Phys. 109 (2011) 123507.

[69] P.J. Martin, Ion-assisted thin film deposition and applications, Vacuum 36 (1986) 585.

[70] K.H. Müller, Model for ion-assisted thin-film densification, J. Appl. Phys. 59 (1986) 2803.

[71] W.M. Lau, I. Bello, L.J. Huang, X. Feng, M. Vos, I.V.Mitchell, Argon incorporation in $\mathrm{Si}$ (100) by ion bombardment at 15-100 eV, J. Appl. Phys. 74 (1993) 7101. 